\title{
Behavioral problems and tobacco use among adolescents in Chile
}

\author{
Luis Caris, ${ }^{1}$ Marianela Varas, ${ }^{1}$ Christopher B. Anthony, ${ }^{2}$ \\ and James C. Anthony ${ }^{3}$
}

ABSTRACT Objective. To examine the association between behavioral problems and tobacco smoking among adolescent students in Chile.

Methods. Data were drawn from a study that included questionnaire surveys of 46907 school-attending adolescents in all 13 of the administrative regions of Chile. Assessments were based on an adapted, Spanish-language version of the Drug Use Screening Inventory. The conditional form of the logistic regression model was used for analysis, with matching of students on individual schools, and with further statistical adjustments for sex, age, and selected risk factors.

Results. The prevalence of tobacco smoking among the adolescents was very high across all of Chile, with a level between $56 \%$ and $65 \%$ in each of the 13 regions. The estimated odds of tobacco use in youths at the highest level of behavioral problems was about twice that for youths at the lowest levels, both before and after controlling for sex, age, lack of participation in recreational activities, level of irritability, and levels of problems with school, family attention, and mental health.

Conclusions. These findings help to complement and complete the evidence of prior studies on tobacco smoking among adolescents with behavior problems, including recent research on Central American youths. Although the magnitude of observed associations in Chile was not as great as that for the associations found in Central America, both the strength of these associations and their statistical significance were observed throughout Chile. This is the first study in Chile on potentially causal relationships such as these.

Key words Smoking, social behavior disorders, adolescent, adolescent behavior, Chile.

Vittetoe and colleagues (1) have presented evidence of a potentially causal

1 University of Chile, School of Public Health, Santiago, Chile.

2 Johns Hopkins University, Baltimore, Maryland, United States of America.

3 Johns Hopkins University, Bloomberg School of Public Health, Baltimore, Maryland, United States of America. Send reprint requests to: James C. Anthony, Johns Hopkins University, Bloomberg School of Public Health, 624 North Broadway, ELCID@893, Baltimore, MD 21205, United States of America; fax: (410) 955-9088; e-mail: janthony@ jhu.edu association between behavioral problems and the occurrence of tobacco smoking, based on evidence from school surveys conducted in 1999 in Costa Rica, El Salvador, Guatemala, Honduras, Nicaragua, Panama, and the Dominican Republic. Because tobacco smoking is not a known cause of conduct problems, these results tended to support the hypothesis that the occurrence of tobacco smoking might depend on levels of youthful behavioral problems, measured in terms of behaviors that are harmful to youth development. These behaviors include fighting, swearing, and risky or dangerous activities.

In prior research (2), youthful conduct problems and aggression (e.g., starting fights) have been linked to excess occurrence of drug use, including the level of tobacco involvement, independent of exogenous variables such as disturbances of mood and attention. However, as noted by Vittetoe et al. (1), and more recently by Martini et al. (3), 
this research work has been performed where tobacco smoking may be relatively uncommon or subject to strong social pressures not conducive to tobacco use. As noted by these authors $(1,3)$, there is reason to ask whether these associations linking tobacco use with behavioral or mental health problems will be found in countries where tobacco smoking is more commonplace and less socially stigmatized.

To extend this line of research, we have chosen to focus on a single large Latin American country, Chile, in which tobacco smoking seems to be considerably more prevalent than in most other places in the world. For example, in the United States of America, an estimated $12 \%$ of 8 th-grade respondents, $21 \%$ of 10 th-grade respondents, and $30 \%$ of 12 th-grade respondents were found to have smoked tobacco in the 30 days prior to survey assessment (4). In contrast, within Chile, $27 \%$ of 8 th-grade respondents, $45 \%$ of 10 th-grade respondents, and $54 \%$ of 12th-grade respondents had smoked tobacco in the 30 days prior to survey assessment (5). As such, the prevalence of recent smoking among young people in Chile is some two to three times as high as in the United States.

For this study, we analyzed epidemiological surveillance data from all of the 13 administrative regions of Chile in order to estimate the association between levels of behavioral problems and tobacco smoking, with a methodological approach and statistical adjustments essentially the same as those used by Vittetoe and colleagues (1). What is especially noteworthy about this methodological approach is its capacity to hold constant socially shared determinants of tobacco smoking that otherwise might confound attempts to estimate the degree to which occurrence of tobacco smoking depends on levels of behavior problems. For example, students enrolled in a single school are exposed to a socially shared environment that might favor or discourage drug use through such factors as the prevalence of peer smoking and lax attitudes toward tobacco smoking. In addition to these shared microsocial influences on occurrence of tobacco smoking, there are other more "macrosocial" influences such as school policies regulating tobacco smoking, billboards that advertise cigarettes or other tobacco products in the vicinity of the school, and ease of purchasing tobacco (e.g., whether nearby stores sell tobacco to minors, or whether cigarettes are sold one by one or only in 20-cigarette packages). The school-matching strategy used by Vittetoe and colleagues, and also used in this study, holds constant these influences, to the extent that they are invariant within classrooms or schools. As such, the research design creates a sharper focus on suspected individuallevel determinants of tobacco smoking such as the behavioral problems that are the primary focus in this line of research.

Chile has one of the highest youth tobacco-smoking prevalence levels of any country in the world, according to the Global Youth Tobacco Survey (6), which was done from 1999 to 2001 in 43 countries around the world, using the same methodology and instrument. Out of 24 countries in the Region of the Americas, Chile had the highest rate of current tobacco users. There is clearly a need to know how to reduce this epidemic of tobacco smoking in the country. The findings from this study and from similar studies may give clues as to what public health measures might be more or less effective in reducing the tobaccosmoking prevalence in both Chile and other nations.

\section{MATERIALS AND METHODS}

The data under study were collected during epidemiological surveys conducted in the 13 regions of Chile, for which the first author (Luis Caris) was the director of the study and principal investigator. The regions of Chile are numbered from north to south, with the Metropolitan Region denoting the city of Santiago and the surrounding areas (Santiago is the capital of Chile and also the country's largest city). The sampling process was one in which public, private, and semiprivate schools were selected according to a stratified design to represent all 13 regions of the country, in accord with the students' proportional distributions by area and type of school from the 62 most populated cities of the country. (Semiprivate schools are private institutions, but they also receive Government funds for each student.) The study sample consisted of students from the 8 th grade to the 12th grade, and aged 12 to 20 years old. Within regions, sample sizes ranged from 414 students (Region XI, Aysén) to 24968 students (the Santiago Metropolitan Region). All respondents were recruited as volunteer participants in the survey, with a total sample size of 49607 students representing the total population of 721989 students from the 8 th to 12 th grades of the 62 cities in all the regions. Selected characteristics of the survey respondents are given in Table 1, displayed in order of region number.

Sample selection was via probability sampling at four levels: the type of school, the individual school chosen, the students' grade, and the students themselves within the school and grade. Each selection resulted in up to 20 students from a given school and grade level.

Although trained interviewers conducted the student survey, the interview was implemented via a standardized anonymous self-report questionnaire. A letter was sent to the parents of each student the day prior to the survey to inform them of the survey and to secure passive consent for the students to participate; the parents could decline to have a child participate by sending a brief communication to the school.

The instrument used was a Latin American adaptation of the Drug Use Screening Inventory (DUSI). The original DUSI instrument was developed by Ralph Tarter and collaborators (7). For the Latin American adaptation, researchers from Central America, Colombia, and Chile translated and back-translated the instrument in order to ensure conceptual equivalence. The Latin American adaptation also included some questions that the original 
TABLE 1. Selected demographic characteristics (in percentages) of the student samples, study of behavioral problems and tobacco use in the 13 regions of Chile, 1999

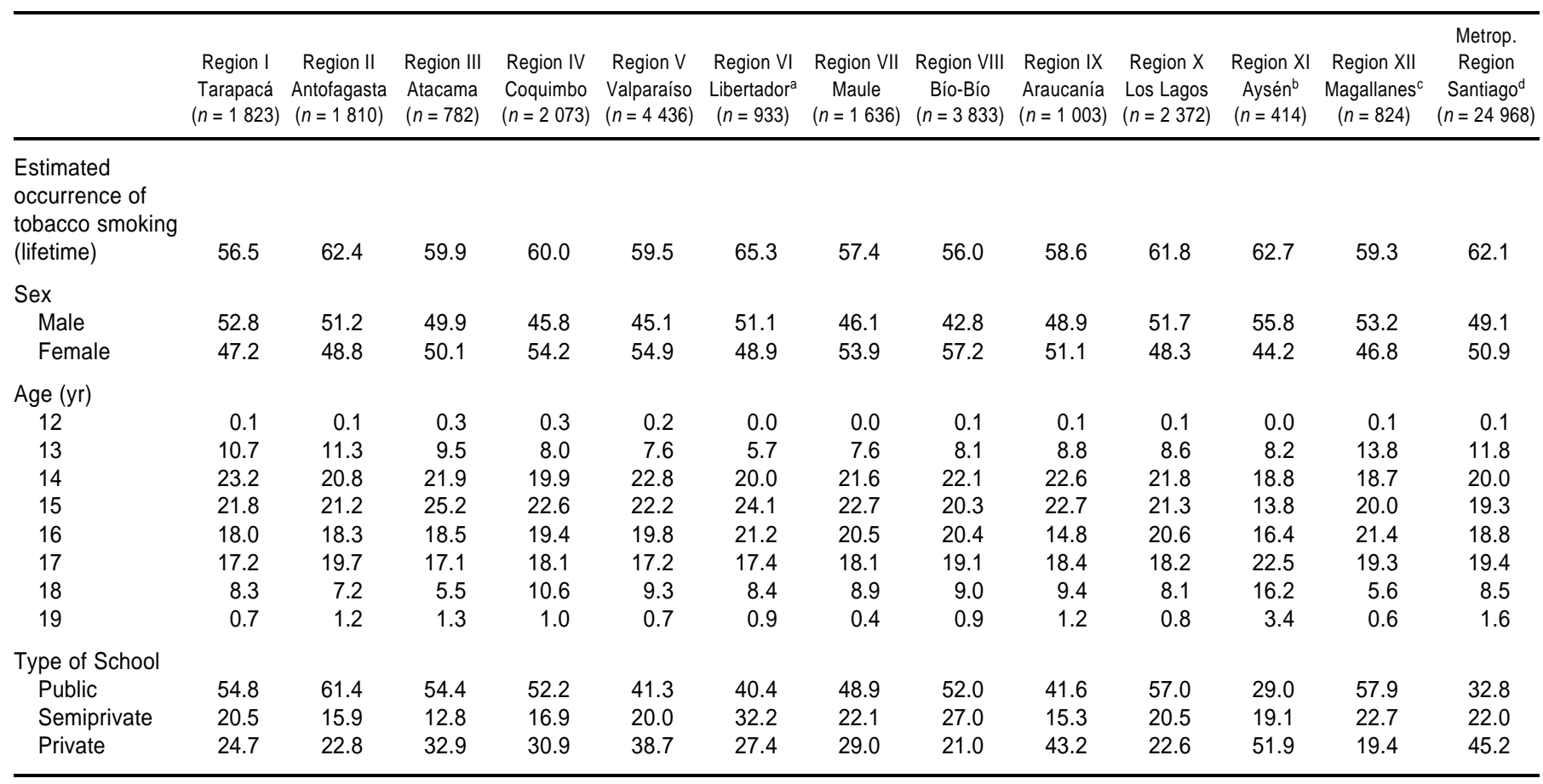

a Libertador General Bernardo O'Higgins.

b Aysén del General Carlos Ibáñez del Campo.

c Magallanes and the Chilean Antarctic.

${ }^{d}$ Metropolitan Region of Santiago.

DUSI did not contain, such as on ever using tobacco and on the recent use of tobacco. The adapted version used in Chile consisted of 115 questions that asked about areas that are hypothesized to be related to tobacco, alcohol, and other drugs. Estimates of prevalence proportions for these analyses were derived by sample probabilities weighted by the total student population. In addition, a latent structure (factor) analysis for the dichotomousformat questions was completed using the MPlus program (8), from which multi-item scales were created.

The latent structure analysis disclosed an identifiable "behavioral problems" dimension, tapped by six items on the youth's behavior. This behavioral problems dimension is consistent with the work reported earlier by Vittetoe et al. (1). The dimension was measured via Spanish-language versions of the following six items, as- sessed using a dichotomous, Yes (1) No (0) response format and whose total was summarized as a score ranging from 0 to 6 :

- Have you teased or done harmful things to animals?

- Do you swear or use dirty language a lot?

- Do you tease others a lot?

- Have you threatened to hurt people?

- Do you do risky or dangerous things a lot?

- Have you taken advantage of other people?

The internal consistency estimates for this behavioral problems scale for each of the 13 regions ranged from 0.49 to 0.61 (Cronbach's alpha via Kuder-Richardson formula 20 for dichotomous items). This range is comparable to the range found by Vittetoe and colleagues (1) for the seven coun- tries that they studied. In accord with their approach, in Chile we studied the other six DUSI domains as covariates: irritability, association with deviant peers, family attention (with questions about family monitoring, such as asking if their parents generally knew where they were and what they were doing), lack of participation in recreational activities, school problems, and mental health problems. As in the earlier work by Vittetoe et al. (1), in Chile the internal consistency estimates for these other domains were at about the same level or above the ones for the behavioral problems domain.

Except for the MPlus factor analyses, all analyses of data were conducted using version 7.0 of the Stata statistical software package (9). As in the earlier work by Vittetoe and colleagues (1), our initial explorations of the frequency distributions in Chile showed that a large number of respon- 
dents received a score of zero due to the generally low occurrence of reported behavior problems. Therefore, we used the same three-category approach described by those researchers in defining levels of behavioral problems. Students with the lowest level of behavioral problems (a score of 0 ) were placed in the first category, those with a medium level of behavioral problems (scores of 1 to 3 ) were placed in the second category, and those with a high level of behavioral problems (scores of 4 to 6) were placed in the third category. The first category was used as a reference category, against which we measured the second and third categories in order to obtain estimates for the odds ratios indicating the association between tobacco smoking and the indicated level of behavioral problems. There were 9237 students in the reference category, with no behavioral problems; 25793 showed moderate behavioral problems; and 11877 showed the highest levels of behavioral problems.

To accommodate the multiregional and multischool structure of the Chile sample, students were grouped into strata, or risk sets, defined by the school in which they were enrolled at the time of the sampling. As mentioned earlier in this article, this matching strategy holds constant the potentially confounding effects of unmeasured social characteristics within a single school, to the extent that these characteristics are socially shared, including unmeasured peer influence, tobacco availability, local advertisements, and local enforcement of tobacco laws. As a result, all of the tobacco nonsmokers attending the same schools serve as non-case controls. This statistical method is essentially the same as that used by Vittetoe and colleagues (1) and has been used extensively in prior studies of drug use in order to account for potentially distorting influences of unmeasured, socially shared characteristics $(10,11)$.

The conditional form of multiple logistic regression is an appropriate statistical procedure when cases and noncases are grouped into schools or local area segments $(12,13)$, and we used this procedure to assess the association between the level of behavioral problems and the occurrence of tobacco smoking. The model was then extended to include statistical adjustment for the hypothesized influence of sex (male/female), age, and other suspected covariates.

As in standard multiple logistic regression models, in the conditional logistic regression model the occurrence of an event, in this case the odds of tobacco smoking, is estimated as a function of the suspected causal influence and covariates. These analyses were conducted for the country as a whole and then separately for each of the 13 regions.

In this report we offer $95 \%$ confidence intervals (CIs) as a gauge of the precision of the odds ratio estimates. $P$ values are reported as an aid to interpretation, although we note that the overall size of the sample $(n=46907)$ is one that is conducive to relatively small $P$ values under the null hypothesis, all else being equal. In consequence, we recommend focus on the odds ratio estimates and their 95\% CIs, with the $P$ values regarded solely as a gauge of the statistical strength of the evidence against the hypothesis that there is actually no true association between behavioral problems and occurrence of tobacco smoking in this study.

\section{RESULTS}

The region in which we found the greatest proportion of tobacco-smoking students was Region VI (Libertador General Bernardo O'Higgins), with $65.3 \%$ of the student respondents reporting that they had smoked tobacco at least once. The region in which we found the lowest proportion of tobacco-smoking students was Region VIII (Bío-Bío), where $56.0 \%$ of respondents reported that they had smoked tobacco at least once (Table 1). As mentioned earlier in this article, smoking prevalence rates for adolescents in Chile are much higher than they are for adolescents in the United States. The rates in Chile are also much higher than the ones that Vittetoe et al. found in the seven countries that they studied, which ranged from $3.4 \%$ in the Dominican Republic to $25.5 \%$ in $\mathrm{El}$ Salvador (1).

Table 2 shows the results of the conditional logistic regression analyses for the 13 regions as a whole, and for each region individually, with and without statistical adjustment for selected covariates but with matching on classroom to constrain socially shared determinants of smoking. There was an overall positive association found between the presence of behavioral problems and occurrence of tobacco smoking among students. Specifically, tobacco smoking was about 1.8 times as likely to occur among students with moderate behavioral problems, and it was about 2.0 times as likely to occur among students with severe behavioral problems, as compared to those students with none of these problems (unadjusted relative odds for both moderate and severe behavioral problems, $P<0.001)$. As shown in Table 2, the association between behavioral problems and tobacco use did not appreciably change after adjustments for sex, age, and the aforementioned six covariates (i.e., association with deviant peers, irritability, family attention, lack of participation in recreational activities, school problems, and mental health problems).

The bivariate analyses for each region showed a generally consistent positive association between behavioral problems and tobacco smoking. In most of the 13 regions, the odds of tobacco smoking were typically about twice as high in the group containing youths with the highest level of behavioral problems as compared to the reference group, with or without statistical adjustments.

\section{DISCUSSION}

The main finding of this research is that there is a slight-to-moderate association between levels of behavioral problems and occurrence of tobacco smoking among the youths sampled for the nation of Chile as a whole, and for most of the regions therein, even 
TABLE 2. Estimated association (odds ratio (OR) and $95 \%$ confidence interval (CI)) between levels of behavioral problems and occurrence of tobacco use, according to results of conditional regression analyses for the 13 regions of Chile individualy and for the country overall, 1999

\begin{tabular}{|c|c|c|c|c|c|}
\hline \multirow{2}{*}{$\begin{array}{l}\text { Region/Behavioral } \\
\text { problems }\end{array}$} & Initial Model & Adjusted for sex & $\begin{array}{l}\text { Adjusted for sex } \\
\text { and age }\end{array}$ & $\begin{array}{l}\text { Adjusted for sex, age, } \\
\text { and selected risk factors }\end{array}$ & $\begin{array}{l}\text { Adjusted for sex, age, } \\
\text { and all risk factors }{ }^{b}\end{array}$ \\
\hline & OR $(95 \% \mathrm{Cl})$ & OR $(95 \% \mathrm{Cl})$ & OR $(95 \% \mathrm{Cl})$ & OR $(95 \% \mathrm{Cl})$ & OR $(95 \% \mathrm{Cl})$ \\
\hline \multicolumn{6}{|l|}{ All 13 Regions } \\
\hline Low & 1.00 & 1.00 & 1.00 & 1.00 & 1.00 \\
\hline Medium & $1.77(1.68,1.86)$ & $1.78(1.69,1.87)$ & $1.79(1.70,1.89)$ & $1.79(1.70,1.89)$ & $1.79(1.70,1.89)$ \\
\hline High & $2.03(1.90,2.16)$ & $2.05(1.92,2.18)$ & $2.09(1.96,2.22)$ & $2.09(1.96,2.22)$ & $2.09(1.96,2.23)$ \\
\hline \multicolumn{6}{|l|}{ Region I } \\
\hline Low & 1.00 & 1.00 & 1.00 & 1.00 & 1.00 \\
\hline Medium & $1.86(1.42,2.44)$ & $1.89(1.44,2.49)$ & $1.95(1.48,2.57)$ & $1.96(1.49,2.59)$ & $1.96(1.48,2.58)$ \\
\hline High & $2.10(1.54,2.85)$ & $2.20(1.61,2.98)$ & $2.25(1.65,3.07)$ & $2.27(1.65,3.07)$ & $2.22(1.63,3.04)$ \\
\hline \multicolumn{6}{|l|}{ Region II } \\
\hline Low & 1.00 & 1.00 & 1.00 & 1.00 & 1.00 \\
\hline Medium & $1.99(1.54,2.57)$ & $2.00(1.55,2.58)$ & $1.99(1.54,2.58)$ & $1.99(1.54,2.58)$ & $1.96(1.51,2.54)$ \\
\hline High & $2.70(1.93,3.77)$ & $2.74(1.963 .84)$ & $2.68(1.91,3.76)$ & $2.64(1.88,3.71)$ & $2.61(1.85,3.67)$ \\
\hline \multicolumn{6}{|l|}{ Region III } \\
\hline Low & 1.00 & 1.00 & 1.00 & 1.00 & 1.00 \\
\hline Medium & $1.88(1.25,2.84)$ & $1.92(1.27,2.90)$ & $2.02(1.33,3.08)$ & $2.04(1.37,3.11)$ & $2.14(1.40,3.29)$ \\
\hline High & $1.47(0.94,2.31)$ & $1.50(0.95,2.36)$ & $1.62(1.02,2.58)$ & $1.64(1.03,2.61)$ & $1.71(1.06,2.73)$ \\
\hline \multicolumn{6}{|l|}{ Region IV } \\
\hline Low & 1.00 & 1.00 & 1.00 & 1.00 & 1.00 \\
\hline Medium & $1.82(1.37,2.42)$ & $1.84(1.39,2.45)$ & $1.87(1.40,2.49)$ & $1.87(1.40,2.49)$ & $1.88(1.41,2.50)$ \\
\hline High & $1.97(1.47,2.62)$ & $1.99(1.49,2.65)$ & $2.02(1.51,2.70)$ & $2.02(1.51,2.70)$ & $2.03(1.56,2.71)$ \\
\hline \multicolumn{6}{|l|}{ Region V } \\
\hline Low & 1.00 & 1.00 & 1.00 & 1.00 & 1.00 \\
\hline Medium & $1.66(1.38,2.01)$ & $1.69(1.40,2.04)$ & $1.67(1.38,2.03)$ & $1.69(1.38,2.03)$ & $1.68(1.39,2.03)$ \\
\hline High & $1.63(1.34,1.99)$ & $1.66(1.37,2.02)$ & $1.63(1.34,1.99)$ & $1.63(1.34,1.99)$ & $1.64(1.35,2.00)$ \\
\hline \multicolumn{6}{|l|}{ Region VI } \\
\hline Low & 1.00 & 1.00 & 1.00 & 1.00 & 1.00 \\
\hline Medium & $1.57(1.08,2.28)$ & $1.60(1.10,2.34)$ & $1.67(1.14,2.46)$ & $1.67(1.13,2.47)$ & $1.70(1.18,2.50)$ \\
\hline High & $1.59(1.03,2.46)$ & $1.66(1.07,2.56)$ & $1.74(1.11,2.73)$ & $1.76(1.12,2.76)$ & $1.77(1.12,2.79)$ \\
\hline \multicolumn{6}{|l|}{ Region VII } \\
\hline Low & 1.00 & 1.00 & 1.00 & 1.00 & 1.00 \\
\hline Medium & $2.01(1.52,2.67)$ & $2.04(1.54,2.70)$ & $2.03(1.52,2.69)$ & $2.07(1.56,2.76)$ & $2.10(1.57,2.79)$ \\
\hline High & $2.02(1.48,2.76)$ & $2.05(1.50,2.09)$ & $2.04(1.49,2.81)$ & $2.09(1.52,2.87)$ & $2.10(1.53,2.90)$ \\
\hline \multicolumn{6}{|l|}{ Region VIII } \\
\hline Low & 1.00 & 1.00 & 1.00 & 1.00 & 1.00 \\
\hline Medium & $1.78(1.46,2.18)$ & $1.78(1.46,2.18)$ & $1.80(1.47,2.21)$ & $1.80(1.47,2.21)$ & $1.80(1.47,2.20)$ \\
\hline High & $1.99(1.62,2.45)$ & $1.99(1.62,2.44)$ & $2.06(1.67,2.53)$ & $2.06(1.67,2.53)$ & $2.05(1.66,2.52)$ \\
\hline \multicolumn{6}{|l|}{ Region IX } \\
\hline Low & 1.00 & 1.00 & 1.00 & 1.00 & 1.00 \\
\hline Medium & $1.90(1.25,2.88)$ & $1.91(1.26,2.91)$ & $1.96(1.28,3.01)$ & $2.06(1.34,3.18)$ & $2.05(1.32,3.16)$ \\
\hline High & $2.01(1.33,3.06)$ & $2.08(1.36,3.17)$ & $2.18(1.42,3.35)$ & $2.20(1.43,3.39)$ & $2.22(1.43,3.42)$ \\
\hline \multicolumn{6}{|l|}{ Region X } \\
\hline Low & 1.00 & 1.00 & 1.00 & 1.00 & 1.00 \\
\hline Medium & $1.90(1.51,2.40)$ & $2.02(1.59,2.56)$ & $2.00(1.58,2.54)$ & $1.99(1.57,2.53)$ & $2.01(1.58,2.55)$ \\
\hline High & $1.92(1.46,2.51)$ & $2.07(1.58,2.72)$ & $2.13(1.61,2.80)$ & $2.13(1.62,2.81)$ & $2.14(1.63,2.83)$ \\
\hline \multicolumn{6}{|l|}{ Region XI } \\
\hline Low & 1.00 & 1.00 & 1.00 & 1.00 & 1.00 \\
\hline Medium & $2.19(1.34,3.59)$ & $2.34(1.42,3.86)$ & $2.42(1.46,4.01)$ & $2.43(1.46,4.04)$ & $2.43(1.45,4.06)$ \\
\hline High & $1.43(0.76,2.70)$ & $1.56(0.82,2.98)$ & $1.52(0.80,2.92)$ & $1.52(0.79,2.94)$ & $1.49(0.77,2.89)$ \\
\hline \multicolumn{6}{|l|}{ Region XII } \\
\hline Low & 1.00 & 1.00 & 1.00 & 1.00 & 1.00 \\
\hline Medium & $2.07(1.45,2.97)$ & $2.05(1.43,2.94)$ & $2.06(1.43,2.96)$ & $2.05(1.43,2.95)$ & $2.05(1.43,2.96)$ \\
\hline High & $1.96(1.21,3.17)$ & $2.03(1.25,3.29)$ & $2.00(1.23,3.27)$ & $2.01(1.23,3.27)$ & $1.99(1.21,3.25)$ \\
\hline \multicolumn{6}{|l|}{ Met. R. of Santiago } \\
\hline Low & 1.00 & 1.00 & 1.00 & 1.00 & 1.00 \\
\hline Medium & $1.72(1.60,1.84)$ & $1.72(1.61,1.84)$ & $1.74(1.62,1.86)$ & $1.74(1.62,1.86)$ & $1.74(1.62,1.86)$ \\
\hline High & $2.24(2.04,2.45)$ & $2.25(2.05,2.46)$ & $2.31(2.10,2.53)$ & $2.31(2.10,2.53)$ & $2.31(2.11,2.53)$ \\
\hline
\end{tabular}

a Irritability and association with deviant peers.

${ }^{b}$ Irritability, association with \deviant peers, family attention, lack of participation in recreational activities, school problems, and mental health problems. 
when matching is used to hold constant socially shared aspects of the classroom and local area environments. All the observed associations remained slight to moderate in magnitude when the models were extended to include statistical adjustments for sex, age, and other suspected confounding covariates.

The main thrust of the evidence supports the hypothesis that levels of behavioral problems might influence occurrences of tobacco smoking, even when smoking is rather prevalent (i.e., with $50 \%$ or more of students acknowledging a history of tobacco smoking). At first glance, this set of observations suggests that behavioral problems might be an important determinant of tobacco smoking even where tobacco smoking is quite prevalent among youths. However, we also note that the observed odds ratio estimates from this study in Chile are at the lower end of values observed by Vittetoe et al. for the six countries of Central America and the Dominican Republic (1). The Chile data suggest that at a higher level of overall prevalence of a history of tobacco smoking, the level of association between behavioral problems and tobacco smoking diminishes somewhat. This is possibly due to a much higher level of exposure to tobacco smoking across all levels of behavioral problems.

Some of the main limitations of this study are perhaps the same as the ones that Vittetoe and colleagues described for their work (1). The crosssectional approach used in the Chile study prevents us from making strong causal inferences about the association between behavioral problems and tobacco use; prospective and experimental studies of youths are more appropriate to test temporal and causal relationships between behavioral problems and tobacco smoking. Nonetheless, we know of no strong evidence that tobacco smoking causes early behavior problems.
In addition, although the research team has gone to great lengths to ensure that the sample is representative of the actual student population in Chile, the study uses only youths who attend school. Furthermore, the sample is necessarily limited to volunteers, which may bias the results somewhat. Finally, response bias associated with socially desirable reporting and other errors in recognition or recall may affect the results.

However, our Chile study follows Vittetoe and colleagues (1) in examining the suspected causal association between behavioral problems and tobacco use. This study is also the first to examine this association in Chile, where tobacco smoking is quite prevalent. The study's strengths include the use of the conditional logistic regression model, along with a matching strategy based on classroom, in order to control for unobserved social factors within the classroom that might otherwise confound or distort our estimates of the observed association.

The findings of this study support a hypothesis advanced by Kellam and Anthony (14). That hypothesis is that levels of behavioral problems may influence the occurrence of tobacco smoking, even where smoking is a prevalent behavior. The high prevalence of tobacco smoking in Chile has been previously discussed, but it is notable that the prevalence of lifetime tobacco smoking is so high among schoolaged youths that it may itself be distorting a possibly typical association between smoking and behavioral problems. This serious public health problem among students and young adults in Chile merits concern in light of previous studies that have shown an association between adolescent tobacco smoking and later use of other drugs (15).

Although a direct causal association between increased levels of behavioral problems and lifetime tobacco smoking has yet to be firmly established, earlier findings $(2,14)$ as well as the robust and statistically significant odds ratio estimates from our study in Chile seem to indicate such an association. We hope that public health measures appropriate to such an association, such as the Good Behavior Game $(16,17)$, may help in reducing Chile's epidemic of tobacco smoking. The Good Behavior Game was developed more than 30 years ago as a means of improving the behavior and social adaptational skills of children, and it has been revised for use by teachers as a "universal preventive intervention" in primary school classrooms of urban communities within the United States. In three separate replications with rigorous randomized trial designs, the teachers' use of the Good Behavior Game intervention in grades 1 and 2 has been followed by reductions in risk of early-onset tobacco smoking (i.e., starting to smoke before mid-adolescence) $(14,18)$. This reduction has been especially true for boys, and the intervention has other benefits in relation to improved behavior as well. Whether this intervention has value in prevention of tobacco smoking elsewhere in the world is an open question. Given the observed associations between early behavior problems and later risk of teen smoking, and given the health burdens associated with teen smoking, there is good reason to discover interventions that may disrupt the link from early behavior problems to smoking. Universal behavioral interventions of this type, directed toward early antecedents of smoking, may prove to be useful complements to tobacco-focused mass media campaigns, to health education classes, and to other preventive interventions with tobaccospecific content.

Acknowledgements. Data-gathering for this article was supported with funds from the Government of Chile, the National Institute on Drug Abuse of the United States (R01 DA09897), and the United States National Institutes of Health's Fogarty Center (TW005692). 


\section{REFERENCES}

1. Vittetoe F, Lopez MF, Delva I, Wagner F, Anthony JC, and the PACARDO research group. Behavioral problems and tobacco use among adolescents in Central America and the Dominican Republic. Rev Panam Salud Publica 2002;11(2):76-81.

2. Dishion TJ, Andrews DW. Preventing escalation in problem behaviors with high-risk young adolescents: immediate and 1-year outcomes. J Consult Clin Psychol 1995;63(4): $538-548$.

3. Martini S, Wagner FA, Anthony JC. The association of tobacco smoking and depression in adolescence: evidence from the United States. Subst Use Misuse 2002;37(14):1853-1867.

4. Johnston LD, O'Malley PM, Bachman JG. Monitoring The Future national results on adolescent drug use: overview of key findings 2001. Bethesda, Maryland: National Institute on Drug Abuse; 2002. (NIH Publication No. 02-5105).

5. Chile, Ministerio de Educación, Ministerio de Salud y Consejo Nacional para el Control de Estupefacientes. Estudio de diagnóstico del consumo de drogas en población escolar de Chile a nivel comunal. Informe final; mayo 2000. Santiago, Chile: Ministerio de Educación, Ministerio de Salud y Consejo Nacional para el Control de Estupefacientes; 2000.

6. The Global Youth Tobacco Survey Collaborative Group. Tobacco use among youth: a country comparison. Tob Control 2002;11 252-270.

7. Tarter RE, Hegedus AM. The Drug Use Screening Inventory: its application in the evaluation and treatment of alcohol and other drug abuse. Alcohol Health Res World 1991; 15(1):65-75.

8. Muthén \& Muthén. Mplus version 2. Los Angeles: Muthén \& Muthén; 2001.

9. Stata Corporation. Stata 7.0 statistics/data analysis. College Station, Texas: Stata Corporation; 2001.

10. Lillie-Blanton M, Anthony JC, Schuster CR. Probing the meaning of racial/ethnic group comparisons in crack cocaine smoking. JAMA 1993;269(8):993-997.

11. Brunet JS, Ghadirian P, Rebbeck TR, Lerman C, Garber JE, Tonin PN, et al. Effect of smoking on breast cancer in carriers of mutant BRCA1 or BRCA2 genes. J Natl Cancer Inst 1998;90(10):761-766.

12. Bobashev GV, Anthony JC. Use of alternating logistic regression in cases of drug-use clustering. Subst Use Misuse 2000;35(6-8):1051-1073.

13. Wagner FA, Anthony JC. Into the world of illegal drug use: exposure opportunity and other mechanisms linking the use of alcohol, tobacco, marijuana, and cocaine. Am J Epidemiol 2002;155(10):918-925

14. Kellam SG, Anthony JC. Targeting early antecedents to prevent tobacco smoking: find- ings from an epidemiologically based randomized field trial. Am J Public Health 1998; 88:1490-1495.

15. Kandel DB, Yamaguchi K, Chen K. Stages of progression in drug involvement from adolescent to adulthood: further evidence for the gateway theory. J Stud Alcohol 1992;53(5): 447-457.

16. Barrish HH, Saunders M, Wolf MM. Good behavior game: effects of individual contingencies for group consequences on disruptive behavior in a classroom. J Appl Behav Anal 1969;2:119-124.

17. Dolan LJ, Turkkan J, Werthamer-Larsson L, Kellam S. Manual for the Good Behavior Game. Baltimore, Maryland: Johns Hopkins University Prevention Research Center; 1989.

18. Storr CL, Ialongo NS, Kellam SG, Anthony JC. A randomized controlled trial of two primary school intervention strategies to prevent early onset of tobacco smoking. Drug Alcohol Depend 2002;66:51-60.

Manuscript received 18 September 2002. Revised manuscript accepted for publication 21 February 2003.

RESUMEN Objetivo. Examinar la asociación entre los problemas conductuales y el tabaquismo en estudiantes adolescentes en Chile.

\section{Los problemas conductuales y el tabaquismo en adolescentes en Chile}

Métodos. Se obtuvieron datos mediante un estudio en el que se encuestó a un total de 46907 estudiantes adolescentes en todas las 13 regiones administrativas de Chile. Las valoraciones se basaron en una adaptación en lengua española del instrumento Drug Use Screening Inventory. Se aplicó un modelo de regresión logística condicional para efectuar el análisis; los estudiantes fueron pareados por escuelas individuales y se hicieron ajustes en función del sexo, la edad y algunos factores de riesgo.

Resultados. La prevalencia de tabaquismo entre los adolescentes fue muy elevada en todo el territorio de Chile, con cifras que oscilaron entre $56 \%$ y $65 \%$ en cada una de sus 13 regiones. Las posibilidades estimadas de tabaquismo entre los jóvenes con los problemas conductuales más graves fueron alrededor del doble de las observadas entre los que tenían los problemas conductuales más leves, tanto antes y después de hacer ajustes en función del sexo, la edad, la falta de participación en actividades de recreo, el grado de irritabilidad y la magnitud de los problemas de orden escolar, familiar y de salud mental.

Conclusiones. Estos resultados ayudan a complementar y completar los datos aportados por estudios anteriores sobre el tabaquismo en adolescentes con problemas de conducta, incluidos algunos estudios recientes centrados en la juventud centroamericana. Aunque la magnitud de las asociaciones observadas en Chile fue menor que la de las asociaciones encontradas en Centroamérica, tanto la fuerza de estas asociaciones como su significación estadística se constataron en todo Chile. Este estudio es el primero realizado en Chile con el fin de explorar la posible existencia de relaciones causales como las aquí descritas. 